\title{
Mechanical Behavior of Silver Alloys Used as Cast Post and Core in Maxillary Incisors
}

\author{
Flaminio Levy Neto $^{\mathrm{a}}{ }$, Luciana de Moura Brito $^{\mathrm{b}}$, Antônio Carlos Elias ${ }^{\mathrm{b}}$ \\ ${ }^{a}$ Universidade de Brasília, Departamento de Engenharia Mecânica, \\ UnB - FT, ENM, 70.910-900 Brasília - DF, Brazil \\ ${ }^{\mathrm{b}}$ Universidade de Brasília, Departamento de Odontologia, \\ UnB - FS, 70.910-900 Brasília - DF, Brazil
}

Received: July 25, 2003; Revised: September 30, 2003

\begin{abstract}
This experimental "in vitro" investigation is mainly concerned with the mechanical behavior of twenty plastic analogous simulating endodonticaly treated maxillary central incisor roots, divided in two groups, which were restored with: (i) silver (10 specimens, Ag - 80\%); and (ii) silver palladium (10 specimens, $\mathrm{Ag}-58.5 \%$ / $\mathrm{Pd}-27.4 \%$ ) cast alloys. All the restored analogous were clamped inside stainless steel cylinders filled with acrylic resin, and were tested to failure in an INSTRON machine. The static compressive loads were applied with an inclination of $45^{\circ}$ relatively to the longitudinal direction of the teeth. On average, the specimens restored with $\mathrm{Ag}-\mathrm{Pd}$ presented higher values of final failure load (i.e. fracture or excessive plastic bending) and stiffness. On the other hand, those restored with $\mathrm{Ag}$ presented average proportional limit loads which were, in comparison, about $5 \%$ higher.
\end{abstract}

Keywords: mechanical behavior, central incisors, "in vitro" evaluation

\section{Introduction}

During the planning and execution of prosthetic work in clinical dentistry, there is the possibility that the maxillary bone-root system of a particular tooth under treatment is in good condition, but its crown, on the other hand, has an extensive structural damage caused by caries, infiltrations in old restorations or any additional traumatic effect. In such circumstances, part of the original dental structure is lost and needs to be replaced with a suitable artificial material. In addition, a new core may be needed in order to rebuild enough tooth structure to retain the restorations. The mechanical behavior of the different dental alloys commercially available for teeth restorations is, among others, one of the most important factors in clinical decisions, involving anatomical, aesthetic, physiological and economic aspects.

Due to the mastication forces, the teeth are subjected to significant mechanical stresses and, as a result, elastic and even plastic strains may take place in the materials involved ${ }^{1}$. Since any onset of plastic deformation is considered a failure, because it implies a permanent strain, the elastic limit of the materials used as cast post and core, in particular, is a decisive issue in endotontic treatments ${ }^{2}$. When a material is stressed below the elastic limit, the deformations are reversible, so, in such situations, the initial geometry of a body in a free stress state is completely recovered after the mechanical load is removed. Its is also known that the fatigue life of metallic materials is significantly longer when the service stresses do not overcome their elastic limits (i.e. plastic deformations do not occur $)^{3}$.

Within the range of elastic behavior of a material an important parameter is the Proportional Limit (PL), which can be defined as the greatest stress that it will sustain without any deviation from the law of proportionality relating stresses and strains ${ }^{2}$. So, for stresses below the PL all the elastic properties of the material remain constant. Therefore, it is desirable that the stresses acting on a material used in dental load bearing restorations do not exceed the PL during its useful lifetime. In addition, the elastic limit of the metallic alloys used in teeth restoration (e.g. gold, silver and silver-palladium) is normally above the PL and the deformations that take place below such limits are also reversible ${ }^{4}$.

Among the variety of precious metallic materials used

*e-mail: flaminio@unb.br 
in dental applications like gold, palladium and silver, there are significant differences in terms of, for instance, price, elasticity modulus, strength, coefficient of thermal expansion, density, hardness and melting temperature. As far as the cost is concerned, the silver alloys can be regarded as a cheaper choice, relatively to other precious materials. So, it is interesting to evaluate how good is the performance of the silver alloys when other aspects are taken into account. One of the purposes of the present study was to test the mechanical behavior of silver alloys under the action of loads simulating biting forces in central upper incisors.

During the course of this "in vitro" experimental investigation, two different silver alloys from Degussa-Hüls (Silver Pratalloy and Silver Palladium Palliag M), were used in single piece restorations (crown and core) of upper central incisors. The restorations took place on plastic analogous simulating endodonticaly treated roots of upper incisors ${ }^{5}$. The specimens, including the analogous and the restorations were tested to failure in an INSTRON (model 1127) machine.

\section{Materials and Methods}

Twenty identical analogous, $14.9 \mathrm{~mm}$ long, made of transparent thermoplastic polymer (Viade Products Inc., California, USA) were employed in order to simulate the root of an endodonticaly treated upper incisor. Its lateral view is shown in Fig. 1. From the total length, $11.6 \mathrm{~mm}$ is a hollow segment and corresponds to the conduct which is prepared to accommodate the metallic restoration, and the remaining $3.3 \mathrm{~mm}$, at the end of the root, is a solid seal. The top cross section at the hollow segment of the analogous has a triangular face, approximately, as shown in Fig. 2.

The thermoplastic material of the analogous was analyzed using an Infrared Spectrophotometer endowed with Fourier Transform (FTIR - PERKIN ELMER, model 1750). The spectrometric identification suggested that the material is a copolymer of styrene and poly methyl methacrylate ${ }^{6}$.

Two groups of cast silver alloys were used for the restoration of the analogous had the following compositions (per weight $)^{5}$ :

1. Ag - 80\%, Sn - 19\%, Cu - 1\% (Silver Pratalloy Degussa-Hüls), designated as Ag; and

2. $\mathrm{Ag}-58.5 \%-\mathrm{Pd} 27.4 \%, \mathrm{Cu}-10.5, \mathrm{Au}-2 \%, \mathrm{Zn} 1.5 \%$, Ir $0.1 \%$ (Silver Palladium Palliag M Degussa-Hüls), designated as Ag-Pd.

Following a procedure which is described in detail in Brito $^{5}$, based on the direct molding technique, ten $\mathrm{Ag}$ and ten Ag-Pd restorations (post core and crown), geometrically identical, were produced. All the coronary portions of the restorations were $6.5 \mathrm{~mm}$ long, and their Meso-Distal as well as Vestibule-Palatine distances were 4.4 and $3.7 \mathrm{~mm}$, respectively, as shown in Fig. 2 and 3. The shape of the

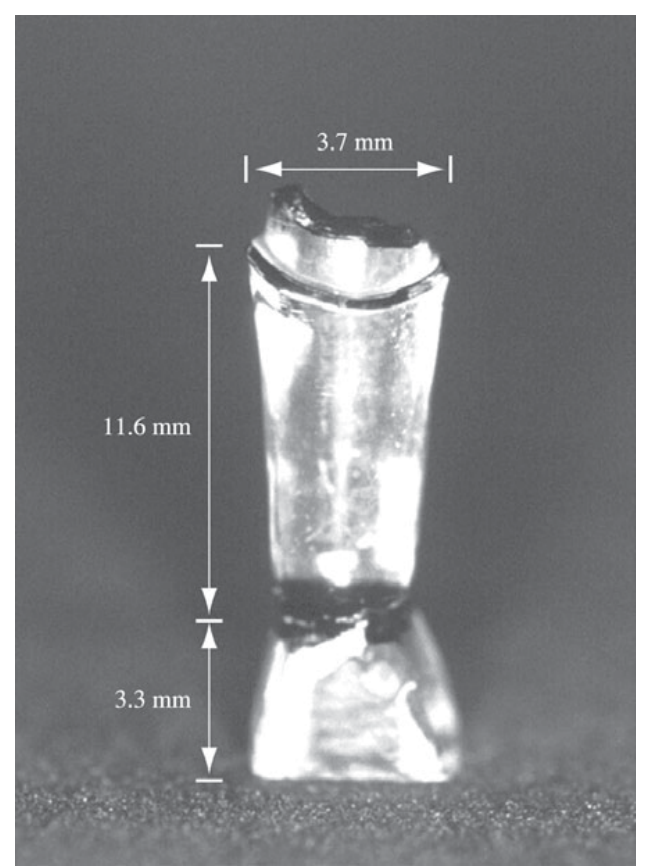

Figure 1. Lateral view of the analogous.

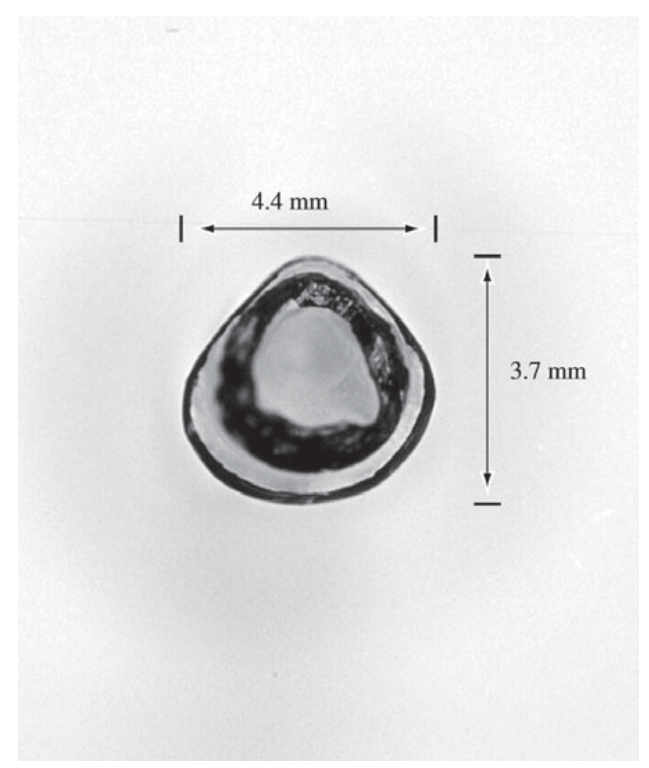

Figure 2. Top view of the analogous.

coronary portion of the initial model was carved and was used as a male mould. From this mould, a nickel-chromium (Kromalit-Knepel) copping was produced and used as a female mould to manufacture the other nineteen cast restorations. The twenty specimens produced in this study were 


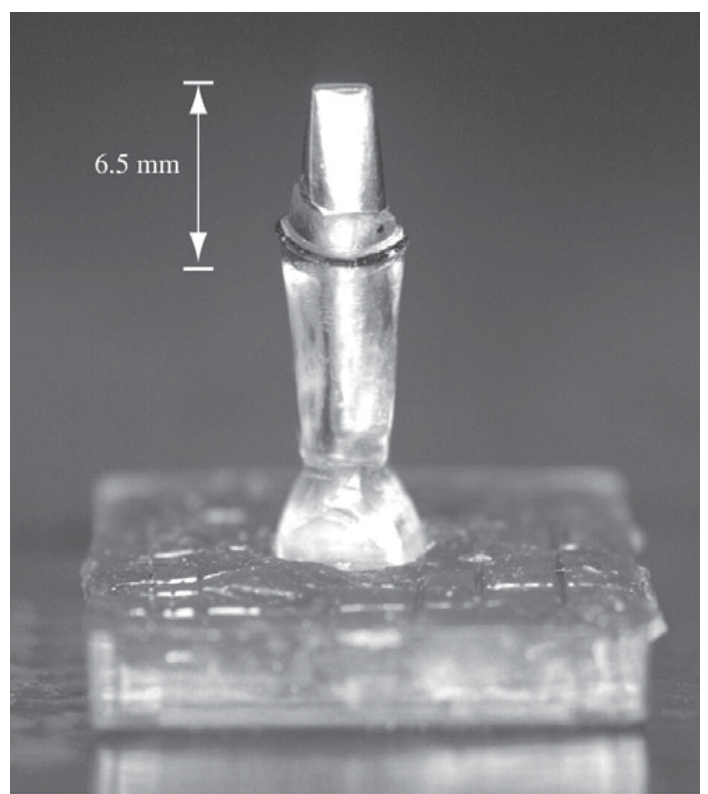

Figura 3. Cast restoration in the plastic analogous.

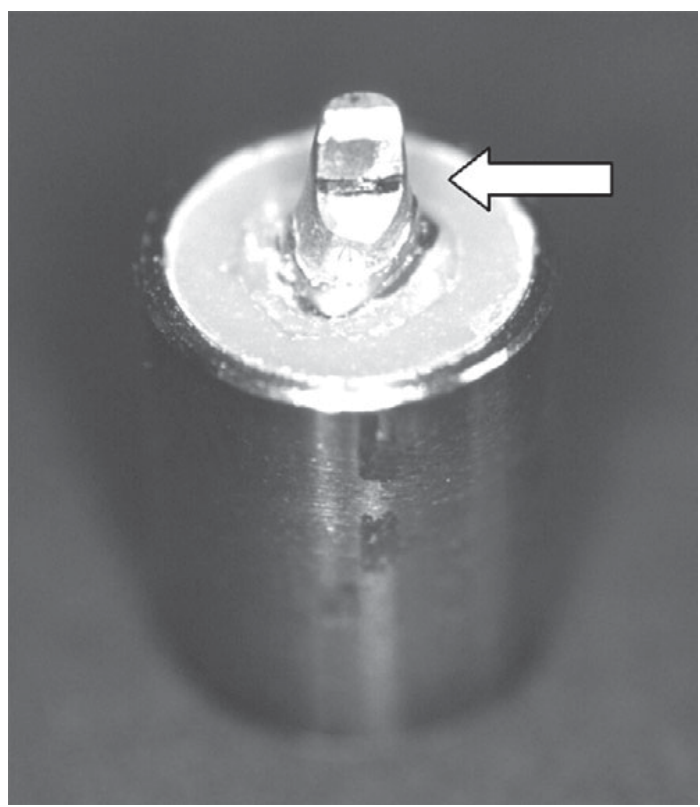

Figure 4. Specimen clamped inside the steel ring.

clamped inside stainless steel rings filled with acrylic resin, as shown in Fig. 4. In addition, in order to facilitate the centralization of the analogous inside the rings, as illustrated in Fig. 5, a Positive Replica of the Restoration (PRR) was also produced, more details about this specific procedure can be found in Brito ${ }^{5}$. The PRR had a cylindrical base and vertical

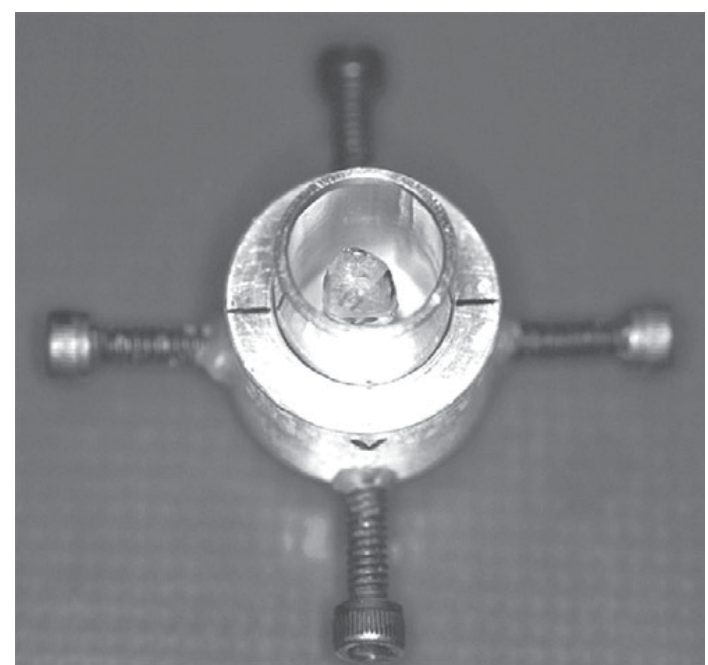

(a)

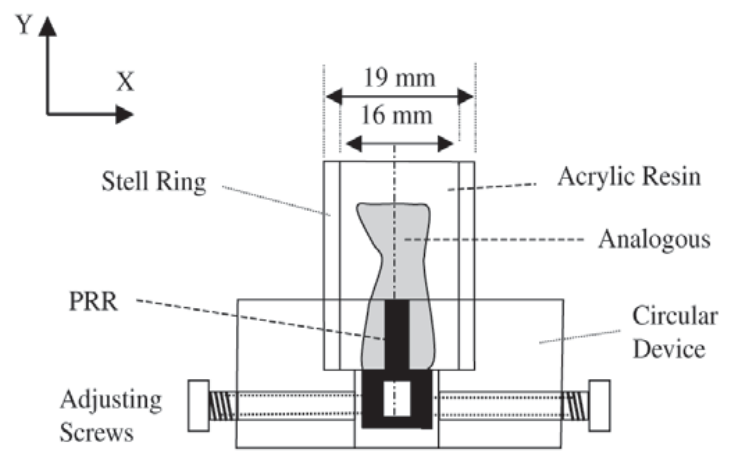

(b)

Figure 5. Schematic view of the device used to centralize the analogous; a) 3-D view of the device; b) cross section view of the vice.

pin. The adaptation of the PRR to the analogous was very $\operatorname{good}^{5}$.

In order to guarantee that both the rings and the teeth were centralized with respect to the same axis (Y), a special circular device with four adjusting screws ${ }^{7}$, perpendicular to each other, as illustrated in Fig. 5a and 5b, was used to hold together, the PRR and the analogous, along the axis of revolution of the rings (Y), during the polymerization of the acrylic resin. The above-described procedure contributed to the repeatability of the test conditions.

With the analogous centralized inside the steel ring, the restorations were cleaned with alcohol and cemented in the plastic roots using zinc phosphate (SS White), as shown in Fig. 4. During the consolidation of the zinc phosphate a load of $26.5 \mathrm{~N}$ (2.7 Kgf) was applied on the coronary sur- 
face of the restorations, using a special purpose device ${ }^{8}$.

Before the tests, a horizontal line, located at about $3 \mathrm{~mm}$ above the surface of the resin, as indicated by the white arrow in Fig. 4, was drawn on the palatine face of the crowns. In all the experiments carried out using the INSTRON machine, the static loads simulating the biting force $(F)$ were always applied on this line. The temporal rate of the displacements during the application of the load $(\mathrm{F})$ was $0.5 \mathrm{~mm} / \mathrm{min}$ in all the tests.

\section{Mechanical Tests of the Central Upper Incisors}

In order to simulate the inclination of $45^{\circ}$ that takes place when the bottom incisor touches the palatine surface of the upper incisor during the mastication process, a special device to hold the steel rings with this inclination during the tests in the INSTRON machine was manufactured ${ }^{7-9}$. The apparatus is basically a solid cylinder of steel, of nominal diameter equal to $50 \mathrm{~mm}$, with an oblique surface at the top end, as illustrated in Fig. 6.

In an experimental study carried out by Dean et al. ${ }^{9}$, to evaluate the influence of endodontic and restorative procedures on fracture resistance of teeth, seventy extracted maxillary human canines, free of cervical caries, were tested to failure in a MTS (model 810) machine, using an apparatus in which the teeth were subjected to a 45 degrees load, applied at a rate of $0.5 \mathrm{~mm} / \mathrm{min}$. The main features of such device were incorporated in the design of the apparatus used in the present work, illustrated in Fig. 6.

The applied force (F) as well as the vertical displacement

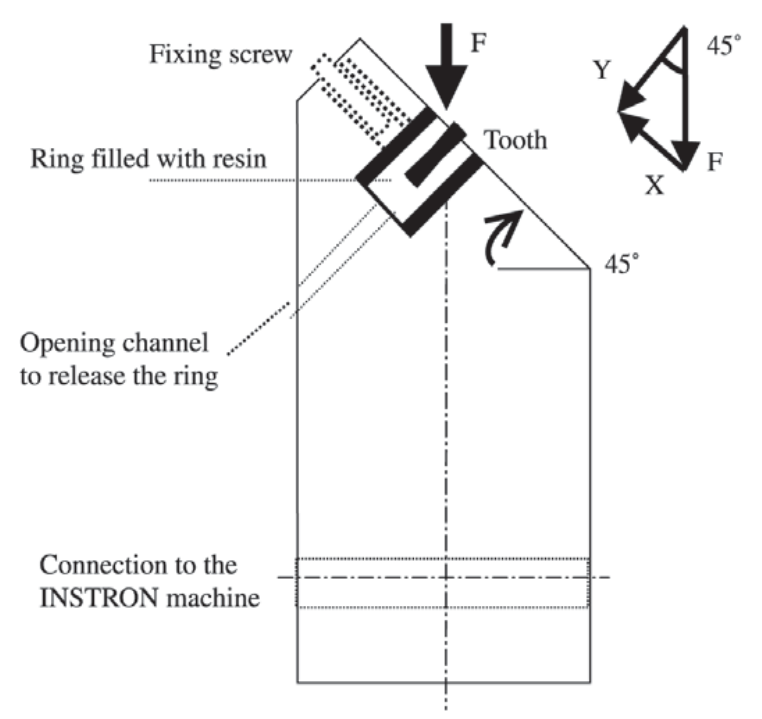

Figure 6. Schematic view of the apparatus used during the tests.
( $\delta$ ) were registered during the course of the experiments. For the specimens restored with $\mathrm{Ag}$ the $\mathrm{F} \times \delta$ diagrams were linear elastic up to about $75 \%$ of the maximum force $\left(\mathrm{F}_{\mathrm{MAX}}\right)$. The Proportional Limit (PL) of a material is a stress below which there is a proportionality relating stresses and strains, and, as far as this work is concerned, the load below which the diagram of $\mathrm{F} \times \delta$ remains a straight line is defined as the Proportional Limit Load (PLL) of a test specimen. The proportional limit load (PLL) obtained for the ten Ag specimens, in this case, varied from 490.5 to $784.8 \mathrm{~N}$, as indicated in Table 1, which lists all the test results of PLL, as well as their averages and the standard deviations (std). For those restored with Ag-Pd, although the values of the maximum force were higher, $31 \%$ in average, the behavior was linear elastic only to about $50 \%$ of the maximum load $\left(\mathrm{F}_{\mathrm{MAX}}\right)$, and the values of PLL varied from 490.5 to $686.7 \mathrm{~N}$.

The diagram $\mathrm{F} \times \delta$ of the $\mathrm{Ag}$ and $\mathrm{Ag}-\mathrm{Pd}$ specimens presented some differences, as illustrated in Fig.7. The average value of $\mathrm{F}_{\mathrm{MAX}}$ of the Ag-Pd specimens was about $31 \%$ higher relatively to the one presented by the Ag specimens. On the other hand, as far as the PLL is concerned, the situation inverted and the average value of PLL of the Ag specimens $(622.9 \mathrm{~N})$ was approximately $5 \%$ higher than the average $(592.4 \mathrm{~N})$ presented by the teeth restored with Ag-Pd. For both kinds of specimens, $\mathrm{Ag}(490.5 \triangle \mathrm{PLL} \leq 784.8 \mathrm{~N})$ as well as Ag-Pd (490.5 $\leq$ PLL $\leq 686.7 \mathrm{~N})$, the values of PLL were always well above the mastication forces for central incisors found in the literature ${ }^{1,2}$, which is about $98.1 \mathrm{~N}$ (10 Kgf).

As indicated in the solid lines of Fig.7, the average vertical displacements, $\delta_{\text {PLL }}$, imposed by the INSTRON machine upon the specimens up to their proportional limit loads, PLL (i.e. end of the linear portion of the $\mathrm{F} \times \delta$ diagrams), were $\delta_{\text {PLLAg }}=0.67 \mathrm{~mm}$, for those restored with $\mathrm{Ag}$, and

Table 1. Proportional Limit Loads (PLL) of the specimens.

\begin{tabular}{ccc}
\hline Tooth & \multicolumn{2}{c}{ PLL (N) } \\
\hline 1 & $\mathrm{Ag}$ & $\mathrm{Ag}-\mathrm{Pd}$ \\
2 & 637.7 & 529.7 \\
3 & 588.6 & 588.6 \\
4 & 686.7 & 490.5 \\
5 & 618.0 & 667.1 \\
6 & 490.5 & 686.7 \\
7 & 588.6 & 627.8 \\
8 & 725.9 & 608.2 \\
9 & 519.9 & 569.0 \\
10 & 784.8 & 549.4 \\
Average & 588.6 & 608.2 \\
Std & 622.9 & 592.5 \\
\hline
\end{tabular}




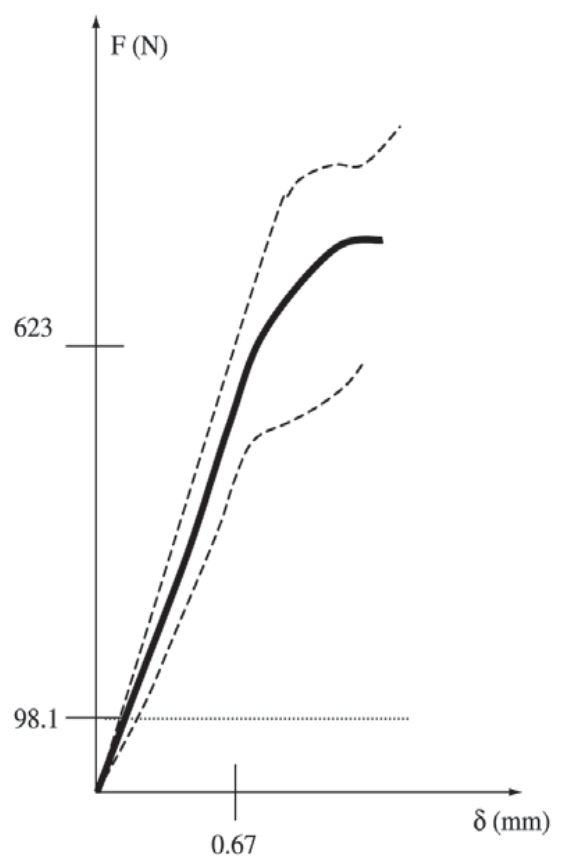

a)

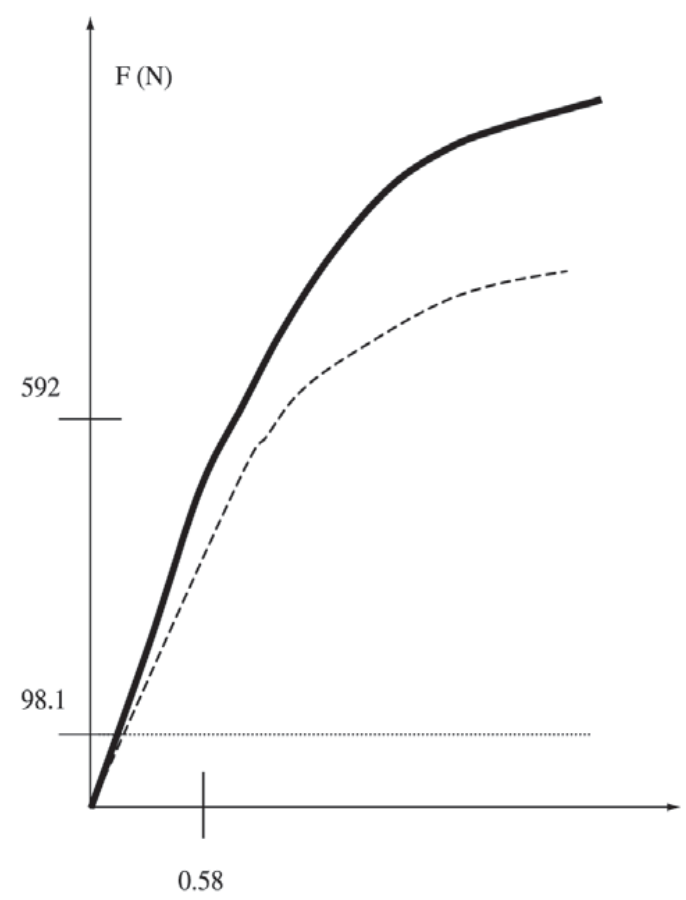

b)

Figure 7. Diagrams $\mathrm{F} \times \delta$ with the average results (solid lines), as well as the best and the worst performances (dashed lines) of the $\mathrm{Ag}$ and Ag-Pd specimens. $\delta_{\text {PLLAg-Pd }}=0.58 \mathrm{~mm}$, for those restored with Ag-Pd. Using the average values of PLL and the corresponding displacements $\delta_{\text {PLLAg }}$ as well as $\delta_{\text {PLLAg-Pd }}$, it was possible to estimate the apparent rigidity presented by the specimens during the tests (i.e. $\mathrm{K}=\mathrm{PLL} / \delta_{\mathrm{PLL}}$ ), which corresponds to inclination of the linear portion of the diagrams $\mathrm{F} \times \delta$. In such calculations it was assumed that the tested teeth models behaved like ideal elastic springs (similar to a cantilever beam subjected to transverse and axial combined forces), when the applied loads F were below PLL (i.e. $\mathrm{F}<\mathrm{PLL}$ ). The average results of the inclinations obtained so far were $\mathrm{K}_{\mathrm{Ag}}=1075.2 \mathrm{~N} / \mathrm{mm}$ and $\mathrm{K}_{\mathrm{Ag}-\mathrm{Pd}}=1084.0 \mathrm{~N} / \mathrm{mm}$, for the specimens restored with $\mathrm{Ag}$ and $\mathrm{Ag}$-Pd, respectively.

The application of the load (F) in an Ag specimen during a test, for $\mathrm{F}<\mathrm{PLL}$, is shown in Fig. 8. It was noticed by inspection, during the course of the tests, that the geometric changes from the initial configuration of the specimens, due to the elastic deformations of the teeth, were slight (i.e. the maximum displacements of the Ag specimens, for $\mathrm{F}=\mathrm{PLL}$ were very small). A similar kind of behavior was also observed for the Ag-Pd specimens, in which the elastic strains were also small. The best and the worst performances of the specimens are illustrated by the top and the bottom dashed

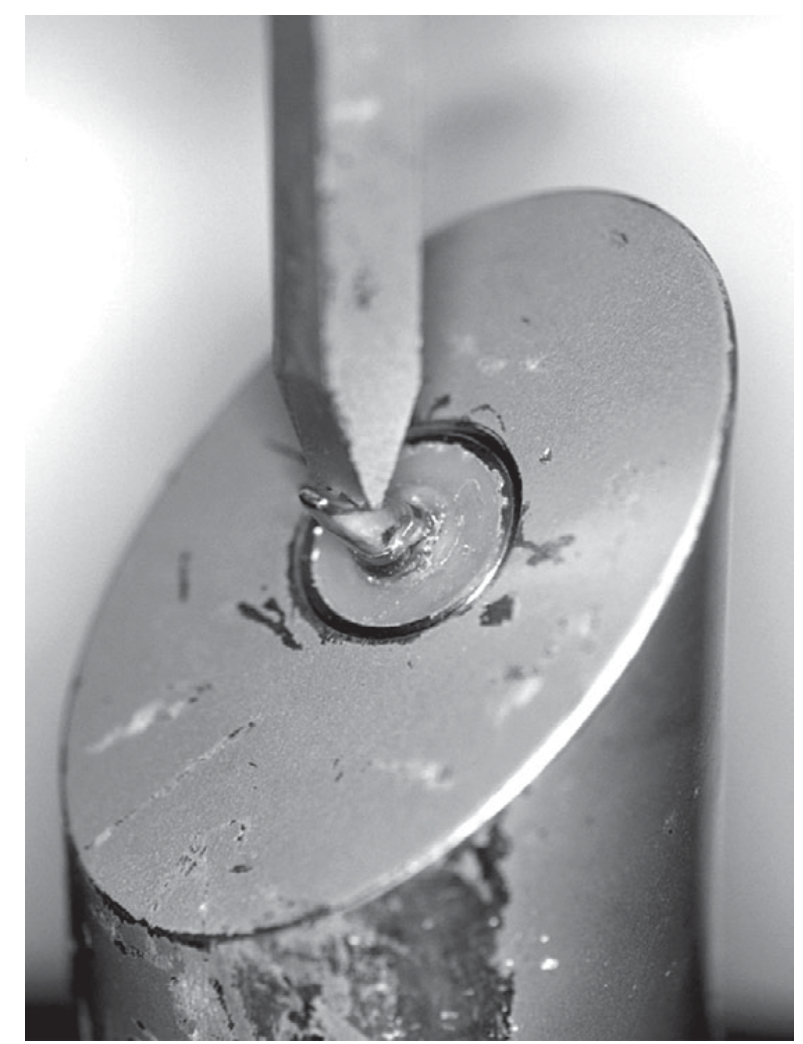

Figure 8. Application of the load $(\mathrm{F}<\mathrm{PLL})$ in a Ag specimen. 
lines in Fig. 7a and 7b, respectively.

Due to a certain degree of ductility presented by the Ag and Ag-Pd alloys used in the present study, most of the specimens did not fracture during the tests. Only three specimens restored with $\mathrm{Ag}$ fracture when $\mathrm{F}=\mathrm{F}_{\mathrm{MAX}}$. In all other cases (i.e. the remaining 7 models reconstructed with cast $\mathrm{Ag}$ and all the $10 \mathrm{Ag}-\mathrm{Pd}$ models) the specimens behave like a plastic hinge for $\mathrm{F}>\mathrm{PLL}$, and $\mathrm{F}_{\text {MAX }}$ was associated with a permanent bending of the models. The plastic bending that took place when $\mathrm{F} \cong \mathrm{F}_{\text {MAX }}$ was rather intense, mainly for the Ag-Pd specimens, as illustrated in Fig. 9. The significant change on the geometric configuration of the AgPd specimens close to the end of the tests, due to the presence of plastic strains that took place for F >> PLL, can be observed comparing the Figs. 8 and 9.

Before the destructive evaluations, two Ag and two AgPd specimens were subjected to initial cycles of loading and unloading static forces, in which the maximum applied forces were: (i) $\mathrm{F}_{1}=196.2 \mathrm{~N}$ (first stage, corresponding to about twice the average mastication force a healthy adult $\left.\mathrm{t}^{1,2}\right)$; and (ii) $\mathrm{F}_{2}=392.4 \mathrm{~N}$ (second stage, with $\mathrm{F}_{2}=2$. $\mathrm{F}_{1}$ ). In such preliminary tests, the behavior of the specimens was practically linear elastic, and, for both kinds of specimens (i.e. $\mathrm{Ag}$ and $\mathrm{Ag}-\mathrm{Pd}$ ), the values of $\mathrm{F}_{1}$ and $\mathrm{F}_{2}$ were about $1 / 3$ and $2 / 3$ of PLL. These results indicate that, after single cycles of loading and unloading forces, of magnitude up to approximately four times the average mastication force found in the literature ${ }^{1,2}$, the restored teeth did not show any evidence of damage.

\section{Discussion of the results}

The Proportional Limit Load (PLL) of all the twenty

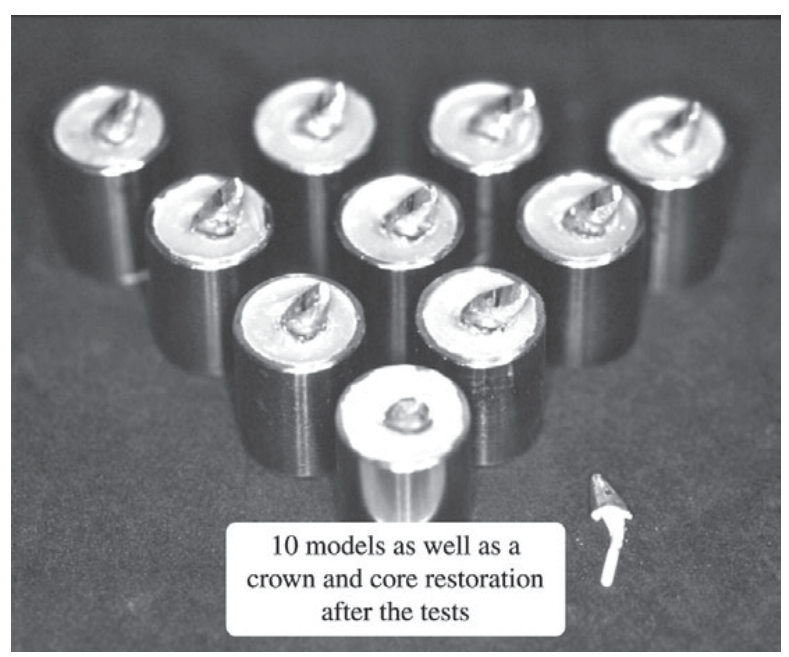

Figure 9. Ten Ag-Pd specimens after the destructive evaluation. specimens restored and tested to failure in the present study were well above the mastication force involving upper central incisors found in the literature (about $98.1 \mathrm{~N}$ or $10 \mathrm{Kgf}^{1,2}$ ), by a factor of at least six times in the worst case. Such results indicate that both kinds of alloy (i.e. Ag and Ag-Pd) are adequate for clinical use from a mechanical behavior point of view. This means that, for loads up to the value of an average mastication force $(98.1 \mathrm{~N})$, with a margin of safety of at least six, the behavior is linear and elastic, as shown in Fig. 7a and 7b. Therefore, under the action of an inclined force of $98.1 \mathrm{~N}$, none of the tested specimens would present any permanent deformation or change in the stiffness. In addition, the elastic displacements were small in all the tests $(<0.7 \mathrm{~mm})$.

The failure mode of three, out of ten Ag specimens, was fracture associated with little plastic deformations (i.e. slightly brittle failure). For the remaining seven specimens fracture did not take place, and the failure was associated with a plastic bending that caused moderate permanent deformations on them (i.e. rather ductile failure). As far as all the ten Ag-Pd specimens are concerned, fracture was not observed in any of them, the behavior was typically ductile, and the average amount of plastic deformations, observed after the destructive evaluations, was significantly larger in comparison with those of the Ag specimens.

The average values of the apparent stiffness obtained for both groups of specimens in the experiments (Ag, $\mathrm{K}_{\mathrm{Ag}}=1075.2 \mathrm{~N} / \mathrm{mm}$ and Ag-Pd, $\mathrm{K}_{\mathrm{Ag}-\mathrm{Pd}}=1084.0 \mathrm{~N} / \mathrm{mm}$ ) were very close to each other (difference below $1 \%$ ), indicating that, during the linear elastic behavior of the restored analogous tested in this investigation, the global rigidity did not change significantly with the kind of the chosen alloy (i.e. $\mathrm{Ag}$ or Ag-Pd). In fact, the transparent plastic analogous adopted in this study were made of a thermoplastic polymer (copolymer of styrene and poly methyl methacrylate) which probably presents an elasticity modulus in the range 1.6 to 3.4 $\mathrm{GPa}^{10}$, while for the metals $\mathrm{Ag}$ and $\mathrm{Pd}$ the values of elasticity modulus are $76 \mathrm{GPa}$ and $124 \mathrm{GPa}^{10}$, respectively. Therefore, the global stiffness of the restored analogous was probably controlled by the much lower rigidity of the transparent thermoplastic polymer, rather than by the higher stiffness of the metallic alloys (Ag and Ag-Pd) used in the restorations.

In another study, which included finite element simulations of the mechanical behavior of teeth, as well as experiments similar to those described in section 2 of the present work, eight healthy human natural upper central incisors (only with crown preparation and no endodontic treatment), as well as ten healthy roots restored with cast silver, were also clamped in steel cylinders, using acrylic resin, and tested to failure in the same apparatus shown in Fig. 6 and $8^{11}$. The main differences in the additional study ${ }^{11}$, relatively to the present work, were: (i) the numerical 
simulations; and (ii) the fact that natural human roots, instead of plastic analogous, were used in most (18) of the experiments. The eighteen $\mathrm{F} \times \delta$ diagrams in such study were practically linear, almost up to the maximum force $\left(\mathrm{F}_{\mathrm{MAX}}\right)$ applied to the specimens, and all the final failures that took place were typically brittle. The average apparent stiffness obtained were: (i) $\mathrm{K}_{\mathrm{NT}}=1888.4 \mathrm{~N} / \mathrm{mm}$, for the natural teeth with crown preparation; and (ii) $\mathrm{K}_{\mathrm{NRRS}}=1739.3 \mathrm{~N} / \mathrm{mm}$, for the natural roots restored with silver. In particular, since the elasticity modulus of the dentin (about $18.6 \mathrm{GPa}^{11}$ ) is higher than the elasticity modulus of the thermoplastic used in the plastic roots, the natural roots restored with silver (NRRS) should be more rigid than the plastic analogous restored with silver (Ag), and the ratio of rigidities $\mathrm{K}_{\mathrm{Ag}} / \mathrm{K}_{\mathrm{NRRS}}=0.62$ confirmed this expectation.

A final comparison, involving specimens which used natural roots and analogous plastic roots restored with silver, is concerned with their average failure loads $\left(\mathrm{F}_{\mathrm{MAX}}\right)$. The average failure load of the natural roots restored with cast silver was $\left(\mathrm{F}_{\mathrm{MAX}}\right)_{\mathrm{NRRS}}=1088.9 \mathrm{~N}^{11}$, while for the $\mathrm{Ag}$ specimens with plastic root restored with silver, tested in this work, the average failure load was $\left(\mathrm{F}_{\mathrm{MAX}}\right)_{\mathrm{Ag}}=859.3 \mathrm{~N}$. The ratio $\left(\mathrm{F}_{\mathrm{MAX}}\right)_{\mathrm{Ag}} /\left(\mathrm{F}_{\mathrm{MAX}}\right)_{\mathrm{NRRS}}=0.79$ indicated that the experimental loads involved in "in vitro" destructive evaluations of specimens of natural roots and analogous plastic roots of upper central incisors restored with cast silver are close to each other. So, in both situations, the cast silver cores used in the restorations were subjected to comparable deformations. In addition, since the plastic roots are more flexible than the natural roots, if, hypothetically, the geometry of both restorations is the same, the deformations of the silver core would be larger when analogous thermoplastic roots, instead of natural roots, are adopted in "in vitro" destructive evaluations. Therefore, due to the greater strains imposed to the metallic core, the use of plastic roots is useful to evaluate the mechanical performance of dental alloys used in restorations of central upper incisors. For the plastic roots restored with $\mathrm{Ag}-\mathrm{Pd}$ the average failure load, $\left(\mathrm{F}_{\mathrm{MAX}}\right)_{\mathrm{Ag}-\mathrm{Pd}}$, was about $1128.1 \mathrm{~N}$. In addition, for the natural teeth $\left(\mathrm{F}_{\mathrm{MAX}}\right)_{\mathrm{NT}}=1030.0 \mathrm{~N}^{11}$, suggesting that the endodontic treatment with cast silver or silver palladium can restore, or even increase, the original strength of comparable healthy central upper incisors.

\section{Conclusions}

Using the procedure presented in this work, to evaluate the mechanical behavior of metallic alloys used in the restoration of central upper incisors, failure loads which are close to the strength of healthy incisors (i.e. about $980.7 \mathrm{~N}$ or $100 \mathrm{Kgf}$ ) can be applied to the specimens composed of a plastic root and a metallic core. In addition, since the loads involved are of the same magnitude, and due to the fact that the plastic root is more flexible than a comparable natural root, for metallic cores of the same geometry, those tested with the plastic roots can be subjected to more intense strains during the experiments. So, the performance of the dental alloys (Ag and Ag-Pd), obtained from the test results presented in this work, is on the conservative side

All the restored analogous tested to failure during the course of this investigation presented proportional limit loads (PLL) well above the average mastication forces of a healthy adult found in the literature, by a factor greater than six. The failure of all the analogous restored with $\mathrm{Ag}-\mathrm{Pd}$, in particular, was typically ductile. None of the Ag-Pd specimens fractured and the mechanism of failure, in all cases, was associated with the formation of plastic hinges in the metallic restorations, as shown in Fig. 9. On the other hand, three of the ten analogous restored with $\mathrm{Ag}$ fractured, whereas the failure of the remaining seven specimens occurred as a result of plastic deformations.

Since the proportional limit load (PLL) is of significant importance, even in comparison with the maximum failure load $\mathrm{F}_{\mathrm{MAX}}$, the specimens restored with $\mathrm{Ag}$ (average $\mathrm{PLL}=622.9 \mathrm{~N}$ ) would be regarded as slightly superior for clinical purposes, relatively to those restored with $\mathrm{Ag}-\mathrm{Pd}$ (average PLL $=592.4 \mathrm{~N}$ ), as far as this aspect of the mechanical behavior, in particular, is concerned. In addition, the relatively lower cost of the silver alloys, relatively to the silver palladium, is another attractive factor for the Ag alloy. However, examining the results presented in Table 1, it is clear from the ratios of the standard deviation over the average PLL $(0.137$, or $13.7 \%$, for the Ag specimens, and 0.097 , or $9.7 \%$, for the Ag-Pd) that the scatter on the values of PLL were lower for the Ag-Pd specimens. Therefore, as far as the PLL is concerned, both alloys can be considered equivalent. The average PLL for the specimens restored with $\mathrm{Ag}$ was about 5\% higher, but the repeatability of the test results for the specimens restored with Ag-Pd was better.

\section{Acknowledgments}

This work was supported by CNPq, process 520.102/98-3.

\section{References}

1. Anusavice, K.J. Phillips' Science of Dental Materials, W.B. Saunders Company, New York, 1999.

2. Graig, R.G. Restorative Dental Materials, The C. V. Mosby Company, St. Louis, 1989.

3. Carlson, R.L.; Kardomateas, G.A., An Introduction to Fatigue in Metals and Composites, Chapman \& Hall, New York, 1996.

4. Callister Jr., W.D. Fundamentals of Materials Science and Engineering, John Wiley \& Sons, Inc., New York, 2001.

5. Brito, L.M. Fracture strength of alloys for cast metallic restorations in root analogous of anterior teeth, M.Sc. Dissertation, University of Brasilia, Faculty of Health 
(in Portuguese), 2000.

6. Takahashi, M.F.K., Análise por FTIR da Amostra Denominada PMMA, CTA, IAE, AQI, RE/M17/02, p. 112, 2002.

7. Levy Neto, F.; Luz, C.C.; Barbosa, S.V.; Albuquerque, R.C.; Cimini Jr., C.A. Experimental investigation on the behavior of upper central incisors reconstructed with carbon fiber posts, Proceedings of the Int. Conf. On Mathematics and Engineering Techniques in Medicine and Biological Sciences - METMBS'00, ed. F. Valafar, June 26 - 29, Las Vegas, p. 724 - 731, 2000.

8. Luz, C.C. Performance of prefabricated posts subjected to combined compression and shear forces, M.Sc. Dissertation, University of Brasilia, Faculty of Health (in Portuguese), 1999.

9. Dean, J.P., Jaensonne, B.G. and Sarkar, N., In vitro evaluation of a carbon fiber post, Journal of Endodontics, v. 24, n. 12, December, p. 807 - 810, 1998.

10. Ashby, M.F.; Jones, D.R.H. Engineering Materials 1, Pergamon Press, Oxford, 1994.

11. Levy Neto, F.; Ferreira, J.L.A.; Santos, A.M. Stress Analysis of Healthy and Endodontically Treated Central Incisors, proceedings of at COBEM 2003, São Paulo, November, 2003. 